Euskal ikerketen aldizkaria | Revue d'études basques |

Revista de estudios vascos | Basque studies review

$20 \mid 2017$

Numéro $X X$

\title{
Ekialdeko erromantzeetako hitzak euskaraz
}

\section{Julen Manterola}

\section{OpenEdition \\ Journals}

Édition électronique

URL : https://journals.openedition.org/lapurdum/3504

DOI : 10.4000/lapurdum.3504

ISSN : 1965-0655

Éditeur

IKER

Édition imprimée

Date de publication : 1 janvier 2017

Pagination : 89-100

ISBN : 978-2-95534-135-3

ISSN : $1273-3830$

Référence électronique

Julen Manterola, «Ekialdeko erromantzeetako hitzak euskaraz», Lapurdum [Linean], 20 | 2017, Sarean emana----an 01 janvier 2021, kontsultatu 03 septembre 2021. URL: http://journals.openedition.org/ lapurdum/3504 ; DOI: https://doi.org/10.4000/lapurdum.3504 


\section{Ekialdeko erromantzeetako hitzak euskaraz}

Julen MANTEROLA

UPV/EHU

EHHE, Euskaltzaindia

\section{Sarrera modura ${ }^{1}$}

Artikuluxka honetan, zenbait gogoeta aurkeztuko ditut, euskal eremuaren ekialdeko erromantzeetatik euskarara etorritako hiru euskal hitzen gainekoak. Ekialdeko erromantzeez ari naizenean, beraz, gaskoiera, okzitaniera eta aragoiera ditut burutan, euskal eremuaren ekialdea; ez errumaniera.

Hiru hitz horiek uzta, putzu eta deitu dira. Mota ezberdinetako ekarpenak egiten ditu haien azterketak: zenbaitetan, erromantzearen historia hobeki ezagutzeko balio du euskal hitzaren lekukotasunak; bestetan, ordea, euskal lexikoaren historia hobeki ulertzeko balio digute; beste batzuetan, erromantzearen eta euskararen, bien historiarako garrantzizkoak diren datuak ateratzen dira. Egoera horien adibide bana dira putzu, uzta eta deitu, hurrenez hurren. Ororen buru, ekialdeko erromantzeetako hitzek euskararen barrenean izan duten bizitasunaren adierazgarri dira hirurak.

Arrazoi jakin bategatik eskaintzen diot Xarlesi lan hau: berari esker jarri nintzen halako hitzen bidean, beti bezain modu eskuzabalean Wartburgen hiztegi etimologikoaren ale oso bat eskaini zidanean.

\section{Deitu}

Ezaguna da mailegua dela deitu hitza. Azken buruan, latinezko dŭctus du jatorri, baina, bokalismoak salatzen duen bezala, erromantzetik hartua behar du, ez latinetik zuzenean: $\breve{1}$ > e da d̆ctus-en lehen bokalaren bilakaera erregularra, latinetik erromantzerakoa (Company \& Cuétara 2014: 141-2).

1. Joseba Lakarrari eta Iñaki Segurolari eskertu behar diet hitz hauen gaineko eztabaida. 
Partizipioaren bilakaera, beraz, honelako zerbait izango litzateke latin-erromantzean: dicto $>$ decto $>*$ deito $>$ decho. Azken forma hau, latinezko $\breve{1}$ laburrari dagokion -e- duena, leonesez aurki daiteke, eta, euskal eremutik hurbilago, Santanderreko adibide bat ere badakarte Corominasek eta Pascualek (s.v. decir). Ildo beretik, Lapesak esaten digu decho baizik ez dela aurkitzen XIII. mendean Asturiasko sartaldean (1998: 33-4), eta bokalismo hori bera duen italierazko detto partizipioa dakar gogora.

Badirudi decto bera italieraz dokumentatzen dela (Vieusseux 1843: 46), nahiz eta balitekeen idazkera kultista izatea. Wartburgen hiztegian (s.v. dīcere), bestalde, walloniera zaharreko deit-en berri ematen zaigu.

Alabaina, -i- nagusitu da partizipioan, bai Galorromanian bai Iberorromanian, beste adizki batzuen eraginez. Honela diosku Wartburgek: "Das part. perf. hat fast in der ganzen Galloromania -i-, im gegensatz zu lt. düctus. Der vokal ist eben an den des prässenstammes angeglichen worden". ${ }^{2}$ Azalpen bera dakar gaztelaniarako Corominasek (s.v. decir): "cuya i se debe a su vez al influjo de de digo, dice, diga, etc." ${ }^{3}$

Bistan dena, euskarazko deitu esplikatzeko, ezin dugu abiatu -i- orokortu duten forma horietatik, eta erromantzezko *deito bat behar dugu; hala proposatzen du Mitxelenak (FHV 104).

\subsection{Datu berri bat}

Ez da erraza -ei- zaharra duen partizipiorik aurkitzea euskal eremuaren inguruko erromantzeen lekukotasunetan. ${ }^{4}$ Hanssenek izendatuki esaten du dito dela aragoierazko forma, ez deyto/decho; dioenez, Amador de los Ríosek agiri nafar batzuetako datua aipatzen du, baina ez du deyto-rik aurkitu Hanssenek horietan (1980: 418, 14 oh.). Eskura dudan Erdi Aroko corpusean ere ez dut Nafarroako agiri-bildumetan horrelakorik aurkitu, ez gaskoierazko testuetan ez bestelakoetan (corpuserako, ikus Manterola 2015). Horrela bada, justifikazio osoa du Mitxelenak ematen duen forma izardunak.

Datu berri bat aurkeztea da atal honen zeregina. Hona ekarri dudan pasartean, behar dugun deito hori lekukotzen da, 'hots egin' adierarekin, gainera. Pasarte hau Aínsako artxibategiko agiri batean aurki daiteke; Ariasek egin du artxibategi horretako agirien edizioa. 1500eko data dakar interesatzen zaigun agiriak, eta (1) hauxe da pasartea (Arias 2012: 170):

(1) "Prometo agora e a todos tiempos haber por firme, agradable e seguro, todas e cualesquiere cosas que por ditos procuradores mios en las ditas cosas e cerca de aquellas, e en las dependientes emergentes de ellas, en nombre mio sera comparecido, començado,

2. Euskaraz: "Perfektuko partizipioak -i- du ia Galorromania osoan, latinezko düctus-en aurka. Bokala orainaldiko adizkietakoekin berdindu da".

3. Bestelako azalpena ematen du Lapesak, op. cit.: "La forma castellana dicho, con vocal inflexionada por la ch (compárese mucho < mŭltum)".

4. Beharbada deitore hitzean aurki daiteke bokalismo horren paralelorik, Corominasek nahi duen bezala jatorriz lat. düctōrem 'esatari' baldin bada; ikus Agud eta Tovarren hiztegian, s.v. deithoratu. 
demandado, oido, recebido, renunciado, loado, aprobado, dito, feyo e procurado e deitos a dreyto e a juzgado, e lo juzgado pagar con todas sus clausulas viciversas, e aquello no revocar digobligacion de mi persona e todos mis bienes, asi mobles como sedientes, habidos e por haber en todo lugar." [Azpimarra nirea]

Zoragarria da pasarte hau: decir ${ }^{5}$ 'esan, deitu' aditzaren hiru partizipio agertzen dira: ditos eta ditas ditugu balio anaforikoarekin eta dito partizipio arrunt gisa; horietan, 'esan' adiera du partizipioak. Horietaz gain, deitos dugu; 'hots eginak, deituak' esanahia du, itxura guztien arabera, eta euskarazko deitu-ren kide bete-betea da, bai formaz bai esanahiz: hortxe dugu Mitxelenak proposaturiko *deito.

Pentsa daiteke partizipio horietan zatiketa lexiko moduko bat dugula, esanahiaren arabera: batetik, -i- duen partizipioak, dito-k, 'esan' adiera du; balio anaforikoko dito, dita, ditos eta ditas forma honetatik eratortzen dira —erruz agertzen dira agiri-bilduman-. Bestetik, -eiduen partizipioak, deito-k, 'hots egin' adiera du.

Kuryłowiczen lege ezagunaren arabera uler liteke zatiketa hau: bazterreko edo espezializatutako esanahi batekin irauten du forma zaharrak, eta funtzio nagusia hartzen du berriak; horixe izan daiteke deito 'hots egin' zaharraren eta dito 'esan' berriaren kasua.

\subsection{Agiri bilduma bereko clamar 'izena izan' eta apelar 'gora jo (zuzenbidean)'}

Deito 'hots egin' horren familia semantikokoak izan daitezke erromantzezko clamar eta apelar ere: cf. frantsesezko (s')appeller eta gaztelaniazko llamar(se), partikula bihurkaria gorabehera bi adierak izan ditzaketenak, 'izena izan' eta 'hots egin'. Horrela bada, Ariasek editaturiko agiri-bilduma horretan clamar eta apelar aditzak ere bilatu ditut.

Interesgarria da ohartaraztea 'izena izan, izendatu' esanahia clamar aditzaren bitartez adierazi ohi dela agiri-bilduma horretan; horrelako sei adibide aurkitu ditut (azpimarra nirea): ${ }^{6}$

(2) a. "porque l'agua aquella en los ditos puentes son yes clamada Cinca" (2012: $69,1349 \mathrm{koa})$

b. "es a saber la thorre de Buesa et la thorre del Puyal clamadas" (2012: 76, $1362 \mathrm{koa})$.

c. "Et senyaladament a la dita thorre clamada de Buesa, que yes cabo principal de la cosa de la cual thorre clamada del Puyal yes miembro et pertinencia" (2012: 76, 1362koa).

d. "setiados en el termino de la dita vilya d'Ainsa clamado de la Coma" (2012: 80, 1373koa).

e. "situadas en la villa de Ainsa lugar clamado cabo de la villa" (2012: 124, 144lekoa).

Bada clamar aditzaren zazpigarren adibide interesgarri bat:

5. Infinitibo hori ageri da agiri horretan berean, ez dir edo dire modukorik.

6. Ez ditut kontuan hartu latinez idatzitako testuak. 
(3) "Presentes testimonios fueron a las sobreditas cosas los honrrados Johan de Brotho menor de dias, habitante en el lugar de Gueso et Exemeno de Latre, habitante en el lugar de Boyl, clamados et rogados" (2012: 158, 1493koa).

Adibide honetan, ez dut garbi 'izena izan' adiera duen clamados-ek; badirudi 'hots egin' adiera hobeki ezkontzen dela pasarte horretan adierazi nahi denarekin.

Esanahiaren ikuspegitik lotuak egon zitezkeen erromantzezko hitzen argazkia osatzeko, apelar aditzaren adibideak ere bilatu ditut. Agiri-bilduma honetan, ia beti du zuzenbideko 'gora jo' adiera; horrelako bost adibide aurkitu ditut, horietako bat deitos bera agertzen den 1500eko agiri berean (azpimarra nirea):

(4) a. "Et en otra manera, si contra aquesto facian, teniase por agraviado et appellaba del greuge feyto et facedero al senyor rey" (2012: 57, 1326koa).

b. "et levar el dito pleyto entro a definitiva sentencia pasada en cosa juzgada de la cual non podere seer appellado con propias mesiones et expensas del dito noble et mias" (2012: 77, 1362koa).

c. "entro por tanto que por sentencia definitiva i en otra manera sia finido o determinado el dito pleito, question de la cual no podres seyer apellado, suplicado o de nullidat opuesto" (2012: 116, 1426koa).

d. "entro por tanto que por sentencia definitiva justamente dada o en otra manera sia finido et determinado el dito pleyto, question de la cual non pueda seyer apellado o de nullidat opuesto" (2012: 119, 1435ekoa).

e. "E prometo de aquellyas ni de alguna de aquellas no apellar, suplicar, ni de nullidat oponer" (Arias 2012: 169, 1500ekoa).

Bada beste adibide bat, non badirudien apelar-ek beste adiera bat duela:

(5) "A los ondrados et sabios el Justitia et baillo de Boltanya, los jurados et homes buenos de Ainsa, salud et apellada voluntad" (2012: 73, 1352koa).

Ez dakit zer adiera duen adibide honetan apellada-k; badirudi esapide ihartu bat dela, eta ez da erraza 'gora jo' adiera ikustea bertan.

\subsection{Aragoiko deito-ren 'hots egin' adieraz eta deitu-ren adierez}

Aurreko 2.1 eta 2.2 ataletan ikusi dugun bezala, euskarazko deitu-ren kognatu garbia den deitos-ek 'hots eginak' esanahia du aragoierazko adibidean; 'izena izan' adierarako, berriz, clamar aditza erabiltzen da aragoierazko dokumentu horietan. Gogoan izan bedi, bestalde, dito partizipio erregularrak 'esan' adiera duela.

Orotariko Euskal Hiztegia-ri $(\mathrm{OEH})$ begiratzen badiogu, deitu-ren esanahiak bi adiera nagusitan bana daitezke: 'hots egin' eta 'izena izan, izendatu'. Bi hauetarik, OEH-ren datuen arabera, 'izena izan' adiera ez da erabat orokorra antzinako testuetan: bizkaieraz ez da dokumentatzen. Nire ustez, esanguratsua izan daiteke datu hau: hitza ekialdetik, nafararagoieratik, demagun, sartu baldin bazen, eta haren jatorrizko esanahia 'hots egin' baldin bazen, ez da harritzekoa adiera berriagoa den 'izena izan' euskal eremu osora zabaldu ez izana. 
Hipotesi honetan, pentsatuko genuke 'hots egin' $\rightarrow$ 'izena izan' izan zela adieren bilakaera semantikoa.

Baina baliteke, era berean, deitu bi adierekin sartu izana euskaraz, eta bizkaieraz 'izena izan' adierarekin egin zitekeen erabilerak arrakastarik ez izana, iritzi aditzak tinko eutsi ziolako adiera eta erabilera horri mendebaldeko eremuan. Ez da ahaztu behar katalanez 'izena izan, izendatu' adiera ere baduela dir aditzak — dit du partizipioa- Corominesek berak (s.v. dir) nabarmentzen duen moduan, adiera horren adibideak are Kataluniako latin arruntean ere aurki daitezke; aragoieraz ere ezaguna da, Jaca ingururaino, eta katalanarekin mugan diren hizkera okzitaniar batzuetan ere aurki daiteke, gaskoiera barne.

Euskal ekialdeko erromantzeen argazki horri aurkajartzen badiogu adiera hori ez dela arrunta frantsesez, gaztelaniaz eta italieraz (cf. fr. eta ital. dire eta gazt. decir, 'esan' adiera nagusiarekin), euskal hitzaren jatorria are gehiago zehaztu dezakegu: nabarmena da hitzaren Pirinio aldeko jatorria. Badirudi, gainera, 'hots egin' eta 'izena izan' adierak batera doazela — dena dela elkarren arteko lehentasunezko harremana—, 'esan' adieraren aurka, eta, alde horretatik, Aínsako deitos-en 'hots egin' adierak bat egiten du adieren banaketa dialektal erromantze horrekin.

\subsection{Laburpena}

Mitxelenak deitu aditzarentzat proposatutako etimologiaren alde datu berri bat ekarri dut hona: euskarazko deitu azaltzeko, erromantzezko *deito baten beharra ikusi zuen berak, eta Aínsako 1500eko agiri batean aurkitutako deitos 'hots eginak, deituak' bat aurkeztu dut.

Formari begira egin zuen proposamen etimologikoa Mitxelenak, baina esanahiaren aldetik ere esanguratsua da Huescako adibide hori: 'hots egin' adiera du, euskarazko deitu-k duen bezala. Formazko egokitasuna adierarena gehitzen badiogu, hitzaren ekialdeko jatorriaren hipotesia indartu besterik ez da egiten, nire ustez.

Esanahiari buruzko xehetasunetan sakondu dut. Euskal hitzak 'izena izan, izendatu' adiera ere badu, 'hots egin' adieraz gain. Aínsako agiri horietan 'izena izan' adiera hori ez da decir aditzarekin adierazten, clamar aditzarekin baizik. Agiri horietako datua hori izanik ere, ohartarazi dut latinezko düctus-en ondorengo batek inon 'izena izan, izendatu' adiera baldin badu, Pirinio inguruko hizkeretan duela, eta katalanaren adibidea jarri dut.

Euskal hitzaren historia hobeki ezagutzea izan dute helburu ohar hauek, baina iruditzen zait esanguratsuak izan direla lexiko erromantzearen historiarako ere: deito formari izartxoa kendu ahal izan diogu.

\section{Putzu}

Putzu hitzaren lekukotasun zaharrez eta gorabehera historikoez aritzeak ere badakar onurarik erromantzezko hitzaren historia hobeki ezagutzeko.

Aurreko atalean, aipatu dut $\breve{l}>e$ bilakaera gertatzen dela latinetik erromantzerako bidean; berdintsu gertatzen da latinezko $\breve{u}$ bokalarekin, $\breve{u}>o$ gertatzen baita bide horretan, kokagune azentudunean. Baina latinezko pŭteus 'putzu' hitzeko lehen silabako $\breve{u}$ bokalak ez du bilakaera hori izan Galorromaniako erromantze guztietan; honela dio Wartburgek (s.v. püteus): 
Hier besteht ein gegensatz zwischen dem norden und dem süden in bezug auf den vokal. Im süden beruht dieser, wie in den andern rom. sprachen, auf $\boldsymbol{o}(<\mathrm{lt}$. $\breve{u})$, im norden aber auf $u^{7}$

Frantsesezko puits da iparraldeko jokabide itxuraz ez erregularraren adibide. Erromanisten interesa erakarri du salbuespen horrek; hurrengo azpiatalean jaso ditut salbuespen honetaz esandakoak.

\subsection{Galorromania iparraldeko formaren arazoa}

Ongi laburbiltzen ditu Fouchék arazoari eman zaizkion irtenbideak (1937-1939: 2930), eta putti frantzikoaren eragina ere aipatzen du, aukera horien artean. Wartburgek, arazoak ikusten baditu ere, eragin germaniko horren alde egiten $\mathrm{du},{ }^{8}$ eta puits forma -u-dunaren banaketa geografikoa darabil argudio nagusi moduan.

Fouchék baztertu egiten du hizkuntz ukipenaren hipotesi hori, eta erromantzearen barreneko bilakaera bat proposatzen du: bigarren silabako y bokalerdiaren aurreratzearekin lotzen du latinezko $\breve{u}$ bokalaren tinbrea gorde izana; pŭtsyu > *pŭytsyu bilakaera proposatuta, esaten du bi $y$-en beharra dagoela esplikatzeko jatorrizko $\breve{u}$ bokalaren tinbrea gorde izana, eta xehetasun fonetiko gehiagorekin hornitzen du bere azalpena (1937-39: 31-35). Wartburgen kritika nagusia hauxe da: bokalerdiaren aitzinatze horrek ez du paralelo garaikide garbirik.

Artikulu honetan ez dut arazo horretan ez eta bere konponbidean sakonduko. Alabaina, Fouchéren proposamenaren bidetik joko dut, autore horrek gaskoieraren diakronian identifikatzen duen arazo bati erantzuteko asmoz.

\subsection{Gaskoieraren arazoa}

Fouché, bere hipotesi nagusia aurkeztuta, azalpen horretara eraman nahi ditu Galorromanian aurki daitezkeen aldaerak (1937-39: 35-42). Bi eremu bereizten ditu, ipar galo-erromantzea ("gallo-roman septentrional") eta hego galo-erromantzea ("gallo-roman méridional"). Ipar galo-erromantzeko iparraldeko eremuan, puits formara eraman daitezke aldaera guztiak, oro har; horiek azaltzeko ez legoke arazorik, eta hipotesi nagusiaren arabera azalduko lirateke. Eskualde bereko hegoaldeko eremuko hainbat formek, berriz, poiz dute azken buruko jatorri. Horietan, y-ren aurreratzea izanik ere $\breve{u}>0$ gertatu da, itxuraz; Fouchék dioenez, hori azaltzeko analogiazko gertakariak behar ditugu, fonetika hutsetik harago.

Artikulu honen helbururako, interesgarriagoa da hego galo-erromantzez gertatzen dena. Eremu zabal honetan, y-ren aurreratzerik gabeko hizkeretan, pŭtsyu-k probentzal

7. Euskaraz: "Bada hemen aurkajartze bat iparraldearen eta hegoaldearen artean, bokalari dagokionez. Hegoaldean, beste hizkuntza erromantzeetan bezala, $o$ da bokala $(<$ lt. $\breve{u})$, baina iparraldean $u$ da".

8. Ikus berrikiago de la Chaussée ere: "Il n'est nullement invraisemblable que ce vocalisme soit dû à l'influence du francique *PUTTI" (1989: 129). Wartburgek ere *putti dakar, izartxoarekin. 
zaharreko pọtz bezalako formak eman ditu. Alabaina, arazo bat azaleratzen da gaskoierarekin; honela formulatzen du Fouchék (1937-39: 41-42):

Mais une difficulté apparaît avec le gascon. Dans une zone délimitée d'une part par l'Océan Atlantique et les Pyrénées, de l'autre par les pp. 548, 549, 643, 645 (Gironde), 656, 657, 648 (Lot-et-Garonne), 658, 668 (Gers), 686, 694 (Basses-Pyrénées) et 695 (H $\mathrm{H}^{\text {tes }}$ Pyrénées), on trouve en effet les formes provenant de *puts. En l'absence de toute anticipation de $y$, cet $[u]$ a de quoi surprendre. Cependant est-il sûr que dans cette région il n'y ait pas eu anciennement de y au contact avec l'ŭ accentué latin? [Azpimarra nirea]

Arazo honetarako, eta azpimarratu dudan lerroari erantzun bete-betea emateko, berebizikoak suertatzen dira euskarazko datuak, bai Erdi Arokoak bai gaur arte iraun duten beste zenbait leku-izenena.

\subsection{Euskal lekukotasunak eta gaskoiera}

Euskarazko putzu-k ere latinezko puteus du jatorri, azken buruan. ${ }^{9}$ Esanguratsua da OEH-k (s.v) dakarren banaketa dialektala: "La forma más extendida es putzu; los autores vizcaínos usan pozu, y algunos guipuzcoanos potzu"; aditzera ematen du jatorri erromantze ezberdinetako item lexikoak ditugula euskaraz. Besteak beste horregatik esan dezakegu erromantze jatorrikoa dela putzu, ez dela zuzenean latinetik hartua; euskaraz lehen silaban -u- izatea, beraz, ez da argudio bat erabakitzeko latinetiko mailegua dela.

Jatorri erromantze horren alde daude hitzaren aldaeren txistukariak ere: autore bizkaitarren pozu gaztelaniazko pozu-tik hartua dateke, eta gipuzkoarren potzu hibrido bat izan daiteke, putzu-rekin gurutzatuta. Bistan da, ekialdetik sartua dirudi putzu afrikatudunak; erraz aurkitzen dira halakoak Galorromanian, ikusi dugun bezala: adierazgarriak direlakoan, cf. bearnes zaharreko 1381eko putz (Lespy \& Raymond s.v.) eta okzitanierako potz bera. ${ }^{10}$

Bitakoak dira hemen aurkeztu nahi ditudan datuak, Fouchéren arazoari erantzuna eman nahian (gogoan har bedi (7)-ko pasarte azpimarratua):

(a) Erdi Aroan, G. Buiçuco (1221), G. Biuchuquo (1229) eta G. Biuçuquo (1235) ditugu; dirudienez, pertsona beraren izenaren aldaerak dira hauek, eta García Larraguetak editaturiko agiri-bilduman aurki daitezke, Nafarroako San Juan de Jerusalén ordenaren agirietan (1957). Badira, jakina, -i- gabeko adibideak hastapeneko herskari ahostunarekin, cf. Sancho Buçuco ( 1245) eta Jimeno

9. Bada euskaraz itxuraz jatorri berekoa den mutio ere, onomastikan lekukotua (ik. OEH s.v.); dirudienez, latinetik hurbilagoko mailegua da hau.

10. Euskaraz, bestela, $t x$ izan ohi da latin-erromantzeko *tj hots multzoaren emaitza (Mitxelena V: 325); ez dirudi, beraz, euskararen barrenean azaldu behar denik putzu-ren tz afrikatu bizkarkaria. Ohar bedi, hala ere, badugula zerbitzu/zerbutxu bikotea ere. Ez dago argi zein den afrikatuaren ahoskunea Erdi Aroko Biuchuquo adibidean. 
Juríok editaturiko Libro Rubro-ko 1339ko Bucçu Ondagauea leku-izen ederra.

Aspaldi dira ezagunak datu hauek eta putzu hitzaren adibidetzat jo ohi dira; ikus Irigarai (1962: 425). Badira, gainera, Putzuko deitura horren kide latin-erromantze esanguratsuak Nafarroan: cf. hainbaten artean 1294ko dompne Alvire de Puteo, Pescadorrek editaturiko bilduman (2000).

Laburbilduz, hauek dira, nire ustez, Fouchéren proposamenaren aldeko daturik esanguratsuenak: -i- bat dute euskal hitzaren aldaera zaharrenek.

(b) Aurki daiteke, beranduago baina Nafarroan bertan — mendebaldean—, antzeko adibiderik: Lana ibarrekoak dira Poyzucoyturria leku-izenaren adibideak, 1708koa Narkuen eta 1710ekoa Galbarran (Jimeno Jurío 1995: 270-4). ${ }^{11}$

Araban ere iraun dute gisa bereko adibide gehiagok: Mezkiako Poizu eta Zalduondoko 1830eko Poizuesioro aurki daitezke López de Gereñuren Toponimia Alavesa lanean (1989: 397), eta Arricopoizu González Salazarren toponimia bilduman (1986: 149). Adierazgarria da zein eskualdetakoak diren hauek: Arabako ipar-ekialdekoak dira, Nafarroako mugatik hurbilekoak. ${ }^{12}$

Honenbestez, euskaraz ere dokumentatuak ditugu -i- duten aldaerak, latinezko puteus-en ondorengoak diren aldaeretan. Ageri denez, hurbileko erromantze batetik hartuko zuten hitza euskal hiztunek, ez ipar galo-erromantzeari; honek iradokitzen du euskararekinukipenean zeuden ekialdeko erromantzeak, nafar erromantzea, aragoiera edo gaskoiera ber a, -i- izan zezaketela. Honetan datza euskal lekukotasunen garrantzia, hizkuntza erromantzeen diakroniari dagokionez: Galorromaniaren eremutik are hegoalderagoko $y$ bokalerdiaren aurreratzearen lekuko dirudite, eta, horrela, beren bitartez ziurta dezakegu ukipenean izan zituen ekialdeko erromantzeetan y bokalerdia izan zuela lehen silaban hitzak. Fouchéren zalantza argitu daiteke horrela.

Bukatzeko, ohar bana egin daitezke euskal lekukotasun harira: bokalerdiaren mugikortasunaren erakusgarri moduan har daitezke Bíuchuquo eta Bịuçuquo —ez dute Builehen silaban-; honek are gehiago indartzen du erromantzezko aldaerekin euskarazko hauek duten lotura, iradokitzen baitu -i- ez zela silaba horretan jatorrikoa, beste nonbaitetik etorria baizik. ${ }^{13}$ Bestalde, badirudi Lana ibarreko eta Arabako lekukotasunak hibrido moduan hartu behar direla eta y bokalerdia sartu zaiola gaztelaniatik hartutako pozu hitzari.

11. Narkuen bada Pouzucoyturria ere, 1705ean; cf. halaber Poyzea Gastiainen, 1708an.

12 Iñaki Carrerari eskertu behar diot Lana ibarreko eta Araia inguruko lekukotasun hauen berri eman izana.

13. Honetan sakonduko ez badut ere, pentsa daiteke honek ondorioak dituela ipar galo-erromantzeko puits formaren xehetasun diakronikoetarako ere: Wartburgen aurka eta Fouchéren hipotesiaren alde, bokal edo bokalerdi horren mugikortasuna erakus lezakete datuok. 


\subsection{Laburpena}

Atal honetan, gaskoierazko berreraiketan izan den problema bat aurkeztu dut: Fouchék dioenez, *puts forma berreraiki behar da latinezko puteus hitzetik datozen gaskoierazko formen berri emateko, baina ezin du azaldu protoforma horren $u$ bokalaren iraupena, ez baitago horretan lagunduko zuen y bokalerdiaren aztarnarik.

Erdi Aroko euskaran eta Araban gaur arte iraun duten zenbait leku-izenetan aurkitu ditut aztarna horiek, gaskoierarekin bateragarria den eremu geografiko batean, euskararenean.

Nire ustez, adibide garbia da hau, nola lagundu dezaketen euskal lekukotasunek bere inguruko erromantzeetako lexikoaren bilakaera hobeki ezagutzen.

\section{Uzta}

Lehen hurbilketan, mailegu izateko aukera asko ditu hitz honek, bere silaba egiturarengatik berarengatik: Lakarraren lanei segitzen badiegu (1995 eta ondokoak), zaila suertatzen da hitz hau CVC egitura duen erro batera eramatea: ez dirudi euskal erro ezagunak direnik uz eta ta.

Schuchardtek berak, duela mende bat baino gehiago, latinezko augustus, *augustare hitzarekin lotu zuen (1912: 39):14 beste lan batean gaztelaniazko agostar 'idortu, kiskali' ematen du paralelo moduan (1914: 74).

Nire ustez, Schuchardten proposamena zuzena da azken buruan, baina zenbait zehaztapen egin behar zaizkio; nagusia, ekialdeko erromantzetik abiatu beharra dagoela, ez gaztelaniatik.

\subsection{Ekialdeko erromantze batetik dator uzta ere}

Ekialdeko erromantzearen jatorriaren hipotesiaren alde, ohartu beharra dago uzta hitza ez dagoela dokumentatua, itxura guztien arabera, ez Arabako euskaraz ez bizkaieraz (OEH s.v.). Zantzu garbia izan daiteke hori, argitzeko hitzaren zabaltzea nondik norakoa izan den euskal eremuaren geografian.

Nire ustez, euskal uzta azaltzeko abiaburu egokiak izan daitezke okzit. avousta edo bearn. aoustà aditzak, nahiz eta esanahiaren aldetik ez izan kide bete-beteak (ikus behean). Ez da erromantzezko izen batetik abiatu behar; euskaraz bada uztatu aditza ere, XVIII. mendeko Haranederrengan dokumentatua (OEH s.v.); aditz hau avousta, aoustà horien edo are frantses zaharreko ouster aditzaren ordaina da, besterik gabe. Horietako formaren batetik abiatuta azaltzen da uzta hitzaren bukaerako - a. Hortaz, uztatu aditzetik atzerantz osatutako hitza da uzta, izen deberbatibo bat da.

Ez dakigu zein izan zen jatorri erromantzearen forma zehatza; bearnesezko aoustà moduko bat izan bazen, pentsatu beharko dugu aurrizki moduan berrinterpretatu zela

14. Gidor Bilbaok ohartarazi nauen bezala, bada Erdi Aroko latinean hitz honen adibiderik, "Metere, messes colligere, quod mense Augusto fit; nostris, Aouster et Ouster, eadem notione et origine" esanahiarekin (DuCange s.v. augustare). 
hastapeneko a-; ez genuke horren beharrik frantses zaharreko ouster moduko batetik abiatuta. Okzitanierazko avousta kontuan hartzen badugu, *busta/buzta bat izango genuke hastapeneko a- berrinterpretatu ondotik; euskararen barrenean bertan azaldu genezake herskari ezpainkari ahostunaren galera, cf. ustel/bustel etab. (FHV 253).

Eztei hitzaren osaeran dugu bilakaera horren paralelo betea: itxura guztien arabera, eztei azaltzeko ezteiatu aditzetik abiatu beharra dago, eta berau mailegu garbia da, cf. fr. zah. festeier, bearn. hesteya (Wartburg s.v. fĕsta); Mitxelenak dakarren bezta + jai/jei osaera baztertu dezakegu horrela (FHV 494, 516).

Ez dut aurkitu gaskoieraz edo okzitanieraz formaren eta esanahiaren paralelo oso-osoa batera biltzen duen erromantzezko aldaerarik. Nire ustez, hori ez da arazo bat. Bearnesezko aoustà-s hitzak "se dessécher sous le soleil" esanahia du, eta okzitanierazko avousta-k "labourer un champ au mois d'août, faire le labour d'août", Wartburgen arabera (s.v. augŭstus (mēnsis)); Aragoin ere aurki daiteke antzeko esanahiarekin agostar: "arar la tierra en el mes de Agosto. Es voz de agricultura usada en Aragón" (NTLLE 1726 s.v.) ${ }^{15}$ Nahiz eta, Wartburgek berak dioenez, Galorromania iparraldetik zabaldutakoa den frantses zaharreko aost 'uzta garaia, uzta' eta aoster 'uztatu' hitzetako adiera, iruditzen zait esanguratsua dela okzitanieraz eta aragoieraz aurkitzea 'abuztuko lanak egin' adiera, 'uztatu'-tik hurbil baitago; holakoen lekukotasuna behar genuen ekialdeko erromantzeetan, euskal hitza azaltzeko.

\subsection{Laburpena}

Nire ustez, argi xamar geratu da uzta hitza ere ekialdeko erromantze horietarik batetik hartua dutela euskal hiztunek, dela gaskoieratik/okzitanieratik dela nafar-aragoiar erromantzetik.

Formaren aldetik, gaskoieraz eta okzitanieraz dauden aditzekin lotu dut uztatu, eta proposatu uzta izena aditz horretatik eratorria dela. Esanahiaren aldetik, frantsesezko eta aragoierazko hitzen adierak ekarri ditut gogora. Ekialdeko jatorriaren hipotesia aldezten du, halaber, euskararen barrenean hitzak duen banaketa geografikoak.

Kasu honetan, ez dirudi euskal hitzaren gorabeherek ezer berezirik dakartenik erromantzezko lexikoaren historian sakontzeko; aldiz, berebizikoa suertatu da erromantzeetako datuak xehakatzea, euskal hitzaren jatorri zehatza ezagutzeko.

15. Cf. gaztelaniazko agostar ere: "Recoger la cosecha en agosto" adierarekin dokumentatzen da 1570etik aurrera (DHLE s.v.). Berceoz geroztik, 'uzta' adierarekin dokumentatzen da agosto bera; euskaraz ere 'uzta' adiera izan dezake abuztu hitzak. 


\section{Bururatze modura}

Artikuluaren hastapenean iragarri bezala, mota ezberdinetakoak izan daitezke euskararen eta ekialdeko erromantzearen lexikoaren gaineko eztabaidaren emaitzak: erakutsi dut ekialdeko erromantzeetako Erdi Aroko datuak esanguratsuak izan daitezkeela bai euskararen bai erromantzeen historiarako; horren adibide izan da deitu hitzaren gaineko eztabaida. Putzu-ren kasuan, berriz, gaskoierazko hitzaren berreraiketan sakontzea ahalbidetu dute euskarazko Erdi Aroko datuek; euskara gertatu da horretan erromantzearentzat lagungarri. Azkenik, uzta-renean, bistakoa gertatu da zein onuragarria izan daitekeen erromantzezko datuei zehatz begiratzea, euskal hitzaren historia hobeki ezagutzeko.

Agian barkatuko nau Xarles Bidegain Castet irakasleak, jauzika ibili bainaiz euskaratik gaskoierara, gaskoieratik okzitanierara eta okzitanieratik aragoierara, euskarara itzultzeko. Irudi luke, edo hala pentsatu nahi nuke, haren deiturak eurak ados direla horrekin, eta ez dut modu egokiagorik aurkitu berari eta bere lanari ohore egiteko. Araiz zuk ere gozatuko zenuen bidaia honetan!

\section{Bibliografia}

Agud, Manuel \& Antonio Tovar. 1990. Materiales para un diccionario etimológico de la lengua vasca VIII. ASJU 24, 615-68.

Arias, Natividad. 2012. Archivo de Ainsa. Colección de privilegios, escrituras y otros documentos (1245-1753) (Fuentes Históricas Aragonesas 65). Zaragoza: CSIC.

Company, Concepcción \& Javier Cuétara. 2014. Manual de gramática histórica. Mexico: Facultad de Filosofía y Letras, Universidad Nacional Autónoma de México.

Corominas, Joan \& José Antonio Pascual. 1991-1997. Diccionario crítico etimológico castellano e hispánico. Madrid: Gredos.

Coromines, Joan. 1980-1991. Diccionari etimologic i complementari de la llengua catalana Barcelona: Curial Edicions Catalanes.

de la Chaussée, François. 1989. Initiation à la phonétique historique de l'ancien français. Nouvelle édition revue et augmentée (Bibliothèque Française et Romane. Série D: Initation, textes et documents 7). Paris: Klincksieck.

DuCange, Pierre Carpentier, Louis Henschel \& Léopold Favre. 1883-1887. Glossarium medice et infimce latinitatis. Niort: L. Favre.

Euskaltzaindia. 1987-2005. Orotariko Euskal Hiztegia. Bilbo:

Fouché, Pierre. 1937-1939. De l'action dilatrice du yod en gallo-roman. Revue des langues romanes 68 , 1-64.

García Larragueta, Santos A. 1957. El Gran Priorado de Navarra de la Orden de San Juan de Jerusalén. Iruñea: Nafarroako Foru Aldundia, Institución Príncipe de Viana.

González Salazar, Jose Antonio. 1986. Toponimia menor de Salvatierra (Cuadernos de toponimia 4). Vitoria-Gasteiz: Arabako Foru Aldundia.

Hanssen, Federico. 1980. Estudios sobre la conjugación aragonesa. Archivos de Filología 
Aragonesa 26-27, 401-18.

Irigarai, Ángel. 1962. Gentilicios del vasco medieval. BAP 18, 423-6.

Jimeno Jurío, José María. 1970. El libro rubro de Iranzu. Príncipe de Viana 120-121, 221-70.

Jimeno Jurío, José María. 1995. Nafarroako toponimia eta mapagintza XXIII. Allín, Lana, Lokiz, Metauten. Iruñea: Nafarroako Gobernua.

Lakarra, Joseba Andoni. 1995. Reconstructing the Pre-Proto-Basque root. In Jose Ignacio Hualde, Joseba Andoni Lakarra \& Robert Lawrence Trask (eds.), Towards a History of the Basque Language (Current Issues in Linguistic Theory 131), 189-206. Amsterdam, Philadelphia: John Benjamins Publishing Company.

Lapesa, Rafael. 1998. El dialecto asturiano occidental en la Edad Media (Serie Lingüística 7). Sevilla: Universidad de Sevilla.

Lespy, Vastin \& Paul Raymond. 1887. Dictionnaire béarnais ancien eta moderne. Montpelhièr: Hamelin Frères.

López de Gereñu, Gerardo. 1989. Toponimia alavesa, seguido de Mortuarios o despoblados y Pueblos alaveses (Onomasticon Vasconiae 5). Bilbo: Euskaltzaindia.

Manterola, Julen. 2015. Euskararen morfologia historikorako: artikuluak eta erakusleak. Tesia, UPV/EHU.

Mitxelena, Luis. 1961-1977[1990]. Fonética Histórica Vasca (ASJUren Gehigarriak 4). Donostia: Gipuzkoako Foru Aldundia.

Mitxelena, Luis. 2011. Obras Completas V. Historia y geografía de la lengua vasca (Anejos del Anuario del Seminario de Filología Vasca Julio de Urquijo 58). Bilbo, Donostia: Euskal Herriko Unibertsitatea, Gipuzkoako Foru Aldundia.

Pescador Medrano, Aitor. 2000. Archivo General de Navarra. Sección de Comptos. Registro $n^{o}$ 6 (1294) (Fuentes Documentales Medievales del País Vasco 106). Eusko Ikaskuntza.

RAE. Diccionario histórico de la lengua española [DHLE]. http://web.frl.es/dh.html

RAE. Nuevo tesoro lexicográfico de la lengua española [NTLLE]. http://buscon.rae.es/ntlle/ SrvltGUILoginNtlle

Schuchardt, Hugo. 1912. Romano-Baskisches. Zeitschrift für romanische Philologie 36, 33-41.

Schuchardt, Hugo. 1914. Zu REV. 7, 475 ff. RIEV 8(1). 73-75.

Vieusseux, Giovan Pietro. 1843. Archivio Storico Italiano. Tomo IV. Firenze.

Wartburg. 1922-2002. Französisches Etymologisches Wörterbuch. Swiss National Science Foundation, CNRS.

Wartburg. 1922-2002. Französisches Etymologisches Wörterbuch. Swiss National Science Foundation, CNRS. 